\title{
The Natural Estrogen Receptor Beta Agonist Silibinin as a Promising Therapeutic Tool in Diffuse Large B-cell Lymphoma
}

\author{
ELENA ORTONA $^{1}$, SILVIA L. LOCATELLI ${ }^{2}$, MARIA TERESA PAGANO ${ }^{1}$, BARBARA ASCIONE $^{1}$, \\ GIUSEPPA CAREDDU ${ }^{2}$, MARIA LUISA DUPUIS ${ }^{1}$, MATTEO MARCONI ${ }^{1}$, CARMELO CARLO-STELLA $^{2,3}$, \\ WALTER MALORNI ${ }^{4,5}$, PAOLA MATARRESE $^{1}$ and MARINA PIERDOMINICI ${ }^{1}$ \\ ${ }^{1}$ Center for Gender Specific Medicine, Istituto Superiore di Sanità, Rome, Italy; \\ ${ }^{2}$ IRCCS Humanitas Research Hospital, Rozzano, Italy; \\ ${ }^{3}$ Department of Biomedical Sciences, Humanitas University, Rozzano, Italy; \\ ${ }^{4}$ University of Rome Tor Vergata, Rome, Italy; \\ ${ }^{5}$ Center for Global Health Research and Studies, Università Cattolica del Sacro Cuore, Rome, Italy
}

\begin{abstract}
Background/Aim: About $40 \%$ of patients with diffuse large cell lymphoma (DLBCL) still have a poor prognosis. Additionally, DLBCL patients treated with doxorubicin are at risk of cardiac failure. Growing evidence suggests an antitumor and cardioprotective activity exerted by estrogen via its binding to estrogen receptor $(E R) \beta$. The aim of this study was to evaluate the anticancer activity of the phytoestrogen silibinin, an ER $\beta$ selective agonist, on DLBCL growth, and its potential cardioprotective effect. Materials and Methods: DLBCL cell lines SUDHL-8, SUDHL-6, and RIVA were used. The anti-tumor activity of silibinin was also evaluated in vivo in NOD/SCID/IL2Rg-/- (NSG) xenografted mice. AC16 human ventricular cardiomyocytes were used to investigate the cardioprotective effects of silibinin. Results: In vitro silibinin induced apoptosis and autophagy, and blocked tumor cell proliferation, also protecting AC16 cardiomyocytes from doxorubicin-induced toxicity. In vivo silibinin induced cell death and autophagy, and reduced tumor volume. Conclusion: Silibinin represents a promising therapeutic tool.
\end{abstract}

Diffuse large B-cell lymphoma (DLBCL) is the most common form of aggressive non-Hodgkin lymphoma (NHL) (1). The standard therapy of this blood malignancy includes rituximab, cyclophosphamide, doxorubicin, vincristine, and

This article is freely accessible online.

Correspondence to: Paola Matarrese, Center for Gender Specific Medicine, Istituto Superiore di Sanità, Viale Regina Elena 299, Rome, 00161, Italy. Tel: +39 0649902010, e-mail: paola.matarrese@iss.it

Key Words: Estrogen receptor $\beta$, silibinin, non-Hodgkin lymphoma, diffuse large B-cell lymphoma, cardiomyocytes, doxorubicin, apoptosis, autophagy. prednisone (R-CHOP). Although this therapy significantly ameliorated the prognosis of DLBCL, up to $40 \%$ of patients still experience relapse or incomplete remission $(2,3)$. In addition, DLBCL patients treated with doxorubicin, the lead compound of anthracycline family, are at risk of cardiac failure due to the drug (4).

Growing evidence indicates an anti-tumor effect of estrogen in lymphoma (5-7). Estrogen exerts its effect by binding to intracellular receptors, namely estrogen receptor (ER) $\alpha$ and ER $\beta$, which act as ligand-activated nuclear transcription factors producing genomic effects (8). In general, estrogen, on one hand, induces proliferation binding to ER $\alpha$, and on the other hand, exerts anti-proliferative and pro-apoptotic effects by binding to $E R \beta$, through activation of different gene expression pathways $(9,10)$. In particular, ER $\beta$ is highly expressed in lymphoid malignancies even though its role as prognostic factor in these tumors is still controversial (11-14). Notably, the activation of ER $\beta$ by synthetic selective agonists, such as KB9520 and diarylpropionitrile, has been demonstrated to inhibit lymphoma growth and its vascularization and dissemination (5-7). By analyzing the mechanisms underlying these effects, we recently observed that the induction of a specific autophagic cascade plays a key role in the ER $\beta$-mediated inhibition of lymphoma growth (7).

Altogether, such evidence encourages the use of ER $\beta$ selective agonists as therapeutic tools in lymphoma management. In addition, recent data support a role for ER $\beta$ in improving cardiac function protecting cardiomyocytes from apoptosis $(15,16)$. Notably, both endogenous and exogenous estrogens have been demonstrated to suppress doxorubicin-induced cardiotoxicity in vivo in female spontaneously hypertensive rats $(17,18)$. This observation extends the possible application of ER $\beta$-targeted agents to management of chemotherapy-induced cardiotoxicity, 
possibly allowing optimal doses of chemotherapy to be used without requiring a suspension or a reduction in the recommended doses.

Phytoestrogens are naturally occurring plant compounds well known to display estrogen-like effects. Among them, the phytoestrogen silibinin, the main active component of silymarin extracted by the milk thistle (Silybum marianum), has been observed to act as agonist of ER $\beta$ displaying a selective binding to this receptor (19). This compound has been used as traditional herbal medication for almost 2,000 years, particularly for its hepatoprotective effects (20). Recent studies also suggest an anti-inflammatory effect and an anti-tumor activity in different cancers, including hematological malignancies such as acute myeloid leukemia, anaplastic large cell lymphoma and multiple myelomas (2025). In particular, the mechanism underlying its antitumor effect seems to involve the induction of autophagic cell death leading to inhibition of cancer cell proliferation, survival, and migration (26). In addition, some experimental studies suggest that silymarin, a complex of compounds including silibinin, exerts cardioprotective effects against doxorubicininduced toxicity both in vitro in rat cardiomyocytes and in vivo in rat models $(17,27-30)$.

Notably, silibinin is available as a dietary supplement and clinical trials have analyzed the safety and efficacy of this compound for the prevention or treatment of different diseases including cancer with promising results (31). However, up to date, no data are available on the possible usage of silibinin as an effective therapeutic option in DLBCL. Hence, the aim of the study was to dissect in vitro and in vivo the ability of silibinin to inhibit tumor growth, modulating autophagy, apoptosis, cell-cycle progression, and proliferation in DLBCL cell lines and in NOD/SCID/IL2Rg-/- (NSG) mice xenografted with DLBCL cell lines. Based on the above reported data regarding the cardioprotective effects of silibinin in rat models $(17,27-30)$, we tested whether this phytoestrogen also protects human cardiomyocytes from doxorubicin-induced toxicity, by analyzing cardiomyocyte cell death, mitochondrial reactive oxygen species (ROS) production, mitochondria membrane polarization, and cytoskeleton alterations, therefore investigating key events in diseases affecting the heart (32).

\section{Materials and Methods}

Cell lines and treatments. The DLBCL cell lines SUDHL-8, SUDHL-6 and RIVA were purchased from the German Collection of Microorganism and Cell Cultures (DSMZ, Braunschweig, Germany). The identity of the cell lines was authenticated by multiplex PCR of minisatellite markers that revealed a unique DNA profile. Cells were also analyzed for the presence of Mycoplasma (Mycoplasma Detection Kit, Invivogen, San Diego, CA, USA) before the beginning of this study. Cells were cultured in phenol red-free RPMI-1640 medium and/or in Iscove's Modified Dulbecco's Medium (IMDM, Gibco BRL, Grand
Island, NY, USA) containing 10\% fetal bovine serum (FBS; Euroclone, Pero, Milan, Italy), $2 \mathrm{mM}$ glutamine (Sigma, St. Louis, MO, USA), and $50 \mathrm{mg} / \mathrm{ml}$ gentamycin (Sigma) at $37^{\circ} \mathrm{C}$ in a humidified $5 \% \mathrm{CO}_{2}$ atmosphere. For estrogen-free cell culture, cells were cultured in phenol red-free RPMI-1640 and/or IMDM medium containing 10\% dextrancoated charcoal-stripped FBS (Euroclone) for 3 days before specific treatments. Silibinin (Sigma) was dissolved in dimethyl sulfoxide and diluted in RPMI-1640 and/or IMDM medium. Preliminary dose response and time course experiments showed that silibinin should be used at a dose of $100 \mu \mathrm{M}$ and at $24 \mathrm{~h}-48 \mathrm{~h}$ culture (depending on the studied parameters) to obtain the highest detectable changes in the absence of toxic effects. Where indicated cells were also treated in the presence of lysosomal inhibitors E64d and pepstatin A (PepA) (both at $10 \mu \mathrm{g} / \mathrm{ml}$; Sigma) for the last $2 \mathrm{~h}$ of culture. AC16 human primary ventricular cardiomyocytes were obtained from MD Millipore Corp. (Temecula, CA, USA). Cell morphology was checked before each experiment, and the number of cell passages after thawing was limited to 20 as previously reported (33). AC16 were seeded in a 6-well plate on day- 1 and allowed to adhere overnight at $37^{\circ} \mathrm{C}$ in phenol red-free Dulbecco's Modified Eagle's Medium/F12 Medium (DMEM, Life Technologies, Carlsbad, CA, USA) containing 10\% FBS (Euroclone), $2 \mathrm{mM}$ glutamine (Sigma), and $50 \mathrm{mg} / \mathrm{ml}$ penicillin/streptomycin (Sigma) at $37^{\circ} \mathrm{C}$ in a humidified $5 \% \mathrm{CO}_{2}$ atmosphere. After this time cells were pretreated for $48 \mathrm{~h}$ with $100 \mu \mathrm{M}$ silibinin or vehicle and then treated with $1 \mu \mathrm{M}$ doxorubicin (Sigma) for $72 \mathrm{~h}$.

Apoptosis, cell proliferation, survival, and cell-cycle. Apoptosis was analyzed using a fluorescein isothiocyanate (FITC)-conjugated annexin $\mathrm{V}(\mathrm{AV})$ and propidium iodide (PI) detection kit according to the manufacturer's protocol (Marine Biological Laboratory, Woods Hole, MA, USA). This assay enables the identification of both early (AV positive/ PI negative) and late apoptotic or necrotic (PI positive) cells. Cell survival was evaluated by incubating cells with $1 \mu \mathrm{m}$ Calcein-AM (Thermo Fisher Scientific, Waltham, MA, USA) at $37^{\circ} \mathrm{C}$ for $30 \mathrm{~min}$. In live cells the nonfluorescent CalceinAM is converted to a green-fluorescent dye.

Proliferation was analyzed by Ki-67 nuclear antigen expression using the phycoerythrin (PE)-mouse anti-human Ki-67 set according to the manufacturer's protocol (BD Biosciences, San Jose, CA, USA). To evaluate cell-cycle progression, cells were synchronized at $\mathrm{G}_{1} / \mathrm{S}$ boundary using $0.7 \mathrm{mg} / \mathrm{ml}$ aphidicolin (Sigma), a specific DNA polymerase inhibitor, for $18 \mathrm{~h}$. Then cells were treated with silibinin, as stated above, or left untreated. Cells were then fixed and permeabilized with BD Cytofix/Cytoperm Buffer and Cytoperm Permeabilization Buffer Plus and analyzed for cell-cycle with the 5bromo-2-deoxy-uridine (BrdU) and the 7-Aminoactinomyocin D (7AAD) solution (BrdU Flow Kit, BD Biosciences). Briefly, cells were stained with $10 \mu \mathrm{M}$ of FITC-conjugated BrdU in the dark for $20 \mathrm{~min}$ at room temperature. After incubation, the cells were washed, resuspended in $500 \mu \mathrm{l}$ staining buffer contains $20 \mu \mathrm{l}$ of 7-AAD solution and processed for flow cytometry analysis. Samples were analyzed by collecting FL2 red fluorescence in a linear scale at 620 $\mathrm{nm}$ and FL1 green fluorescence in logarithmic scale at $512 \mathrm{~nm}$.

Mitochondrial membrane potential. The mitochondrial membrane potential of untreated and treated AC16 cardiomiocytes were studied by using $5-5$ ', 6-6'-tetrachloro-1,1',3,3'-tetraethyl benzimidazolecarbocyanine iodide probe (JC-1; Molecular Probes, Eugene, OR, USA), as previously reported (34). According to this method, living cells were stained with $10 \mu \mathrm{M}$ of JC-1. 
Mitochondrial reactive oxygen species (ROS). Cells $\left(5 \times 10^{4}\right)$ were incubated with $5 \mu \mathrm{M}$ MitoSOX (red mitochondrial superoxide indicator, Thermo Fisher Scientific) in complete medium, for 30 $\min$ at $37^{\circ} \mathrm{C}$.

SDS-PAGE and western blot. Cells were lysed in RIPA buffer [100 $\mathrm{mM}$ tris(hydroxymethyl)aminomethane (Tris)- $\mathrm{HCl} \mathrm{pH} 8,150 \mathrm{mM}$ $\mathrm{NaCl}, 1 \%$ Triton $\left.\mathrm{X}-100,1 \mathrm{mM} \mathrm{MgCl}_{2}\right]$ in the presence of a complete protease-inhibitor mixture (Roche Diagnostics $\mathrm{GmbH}$, Mannheim, Germany). Protein content was measured by the Bradford assay (Bio-Rad Laboratories, Richmond, CA, USA). After SDS-PAGE proteins were transferred onto nitrocellulose membrane (GE Healthcare, Pittsburgh, PA, USA) by means of a Trans-Blot transfer cell (Bio-Rad Laboratories). The membranes were then blocked in 5\% nonfat milk and incubated with the proper antibodies in Tris-buffered saline (TBS) containing $0.1 \%$ Tween 20 and 5\% nonfat milk. Mouse anti-human microtubule-associated protein 1 light chain 3 (LC3-B, Novus Biologicals, Littleton, CO, USA) and rabbit anti-human sequestosome 1 (SQSTM1, Sigma) were used as primary antibodies. Peroxidase-conjugated goat anti-mouse $\mathrm{IgG}$ (Bio-Rad Laboratories) or anti-rabbit IgG (Bio-Rad Laboratories) were used as secondary antibodies and the reactions were developed using the ECL Prime Western Blotting Detection Reagent (GE Healthcare)

To verify the presence of equal amounts of proteins, the membranes were reproved with rabbit anti-human $\beta$-actin (Sigma) antibody. Quantification of protein expression was performed by densitometry analysis of the autoradiograms (GS-700 Imaging Densitometer, Bio-Rad Laboratories).

Immunofluorescence. AC16 cells were fixed with $4 \%$ paraformaldehyde and then permeabilized by $0.5 \%$ ( $\mathrm{vol} / \mathrm{vol}$ ) Triton $\mathrm{X}-100$ as previously described (35). The following primary and secondary antibodies were used: mouse mAb anti-myosin (Abcam, Cambridge, UK), and AlexaFluor 488-conjugated anti-mouse (Invitrogen, Carlsbad, CA). For F-actin detection, cells were stained with tetramethylrhodamine-phalloidin (Sigma) for $30 \mathrm{~min}$ at room temperature. After washing, all the samples were counterstained with Hoechst 33258 (Sigma) and then mounted in glycero/phosphate-buffered saline (ratio 1:1; pH 7.4). The images were acquired by intensified video microscopy with an Olympus fluorescence microscope (Olympus Corporation of the Americas, Center Valley, PA, USA), equipped with a Zeiss charge-coupled device camera (Carl Zeiss, Oberkochen, German).

Mice and treatment conditions. Six- to eight-week-old male NSG mice (20 to $25 \mathrm{~g}$ ) were purchased from Charles River Labs and xenografted with RIVA $\left(10 \times 10^{6}\right.$ cells/mouse $)$ cells by subcutaneous inoculation into the right flank. The treatments started when the tumors were palpable (approximately $200 \mathrm{~mm}^{3}$ ). Siliphos (Indena S.p.A., Milan, Italy), a silibinin-phytosome complex that improves silibinin availability (36), was administered by oral gavage daily at $450 \mathrm{mg} \mathrm{kg}^{-1}$ for 5 days. The control groups received a vehicle ( $0.5 \%$ methyl-cellulose, $\mathrm{pH} 2.2)$ without the active product. The tumors were measured every two or three days with a caliper or were excised and processed for histological analysis. Tumor volumes were calculated using the following equation: $(12 \times \mathrm{w}) / 2$. Tumor growth inhibition was defined as follows $(1-[\mathrm{T} / \mathrm{C}] \times 100)$, where $\mathrm{T}$ and $\mathrm{C}$ represent the mean tumor volumes in the treated group and vehicle-treated control group, respectively. Each experiment was performed on two separate occasions using five mice for treatment group. The animals were euthanized for signs of distress or when the major diameter of individual tumors reached 2 $\mathrm{cm}$ in size. The animal experiments were performed according to EU 86/109 Directive (D.L. 116/92 and following additions) and were approved by the institutional Ethical Committee for Animal Experimentation of the Humanitas Clinical and Research Center.

Histological analysis and immunohistochemistry. Cryostat sections $(8-\mu \mathrm{m}$ thick) of tumor nodules were fixed with $4 \%$ paraformaldehyde and stained with anti-LC3 (Abgent, San Diego, CA, USA) specific antibody. Cell death was detected via TUNEL staining (Roche Diagnostics GmbH, Mannheim, Germany). The sections were analyzed by a light microscope (IX51; Olympus, Tokyo, Japan). Image analysis was performed using the Olympus Cell^ ${ }^{\wedge}$ Imaging software.

Statistical analysis. Statistical analysis was performed with the statistical package Prism 9 (GraphPad Software). In vitro statistical analysis was performed by Mann-Whitney $U$-test. To test the probability of significant differences between the vehicle and silibinin-treated tumor nodules, two-way analysis of variance (ANOVA) was used, and individual group comparisons were evaluated using Bonferroni's test. All measurements were performed at least in three independent experiments. The $p$-values lower than 0.05 were considered significant.

Ethics statement. The animal experiments were performed according to EU 86/109 Directive (D.L. 116/92 and following additions) and were approved by the institutional Ethical Committee for Animal Experimentation of the Humanitas Clinical and Research Center.

\section{Results}

Silibinin induces apoptosis and autophagy in DLBCL cells. To clarify the role of ER $\beta$ selective agonist silibinin in modulating DLBCL cell fate, we first analyzed whether this phytoestrogen could affect apoptosis and autophagy in human DLBCL cell lines, i.e., SUDHL-8, RIVA, and SUDHL-6. To note, after treatment of DLBCL cells with silibinin, a significant increase of the percentage of AVpositive cells was detected $(p<0.05 v s$. untreated cells, Figure 1A). In addition, we observed that silibinin significantly increased microtubule-associated LC3-II and decreased SQSTM1 expression levels in all tested DLBCL cells, this supporting autophagy induction $(p<0.05 \mathrm{vs}$. untreated cells, Figure 1B) (37). In order to confirm this silibinin-mediated effect, a LC3 turnover assay was carried out, using the lysosomal inhibitors E64d and PepA cotreatment. In fact, LC3-II can accumulate because of increased upstream autophagosome formation or compromised downstream autophagosome lysosome fusion (38). To discriminate between these two options, we analyzed silibinin-induced LC3-II accumulation in the presence or absence of E64d and PepA, and we observed, in the presence of these lysosomal protease inhibitors, a further significant $(p<0.05)$ up-regulation of LC3-II level in line 

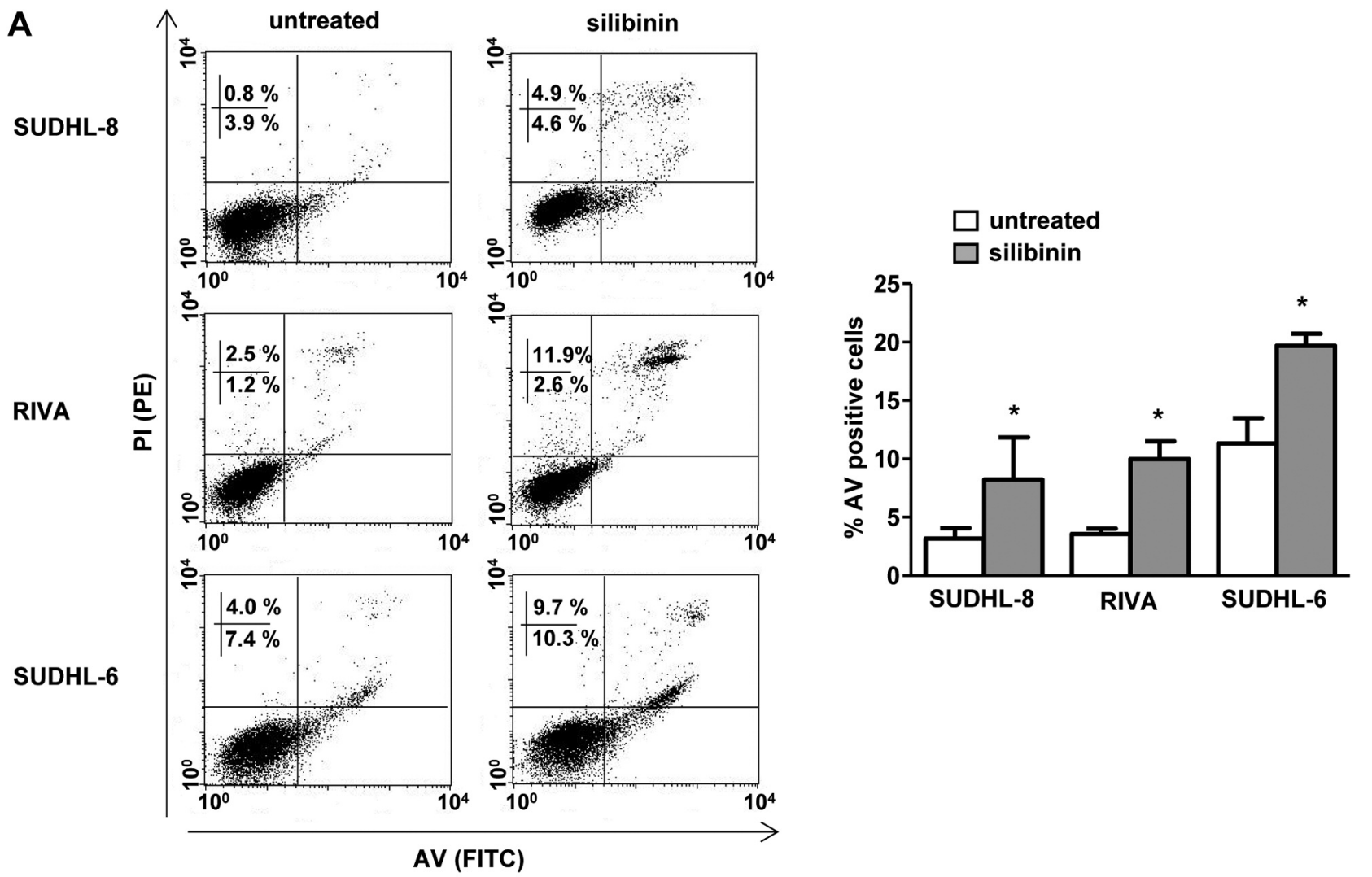

Figure 1. Continued

with an increased upstream autophagosome formation (Figure 1B).

Silibinin blocks cell-cycle progression and proliferation in DLBCL cells. To further clarify the effect of silibinin in lymphoma growth we analyzed the impact of this molecule on cell-cycle progression and proliferation. Interestingly, silibinin was able to significantly increase the percentage of cells in $G_{0} / G_{1}$ phase, suggesting a sharp slowdown in the cell-cycle progression $(p<0.05 v s$. untreated cells, Figure 2A). Moreover, a significant reduction of the percentage of Ki-67 positive cell treated with silibinin was observed indicating that this phytoestrogen affects DLBCL cell proliferation (Figure 2B).

Silibinin inhibits human lymphoma growth in vivo. The antitumor activity of silibinin in NSG mice xenografted with RIVA cell lines was then evaluated. No significant changes in weight or other signs of potential toxicity were detected (data not shown). Silibinin significantly impaired the in vivo growth of RIVA tumor (tumor growth inhibition of $46 \%$, Figure $3 \mathrm{~A}$ ). This finding was paralleled by a strong increase in TUNEL positive apoptotic and necrotic cells (Figure 3B) and in the expression of LC3 (enlarged micrograph displays localized distinct puncta characteristic of LC3-II appearance in autophagic cells, Figure 3C).

Silibinin protects cardiomyocytes from doxorubicin-mediated toxicity. As stated before, R-CHOP is the standard treatment for DLBCL (3). However, one of its components, i.e., doxorubicin, may induce early and late cardiotoxicity (4). Although the exact mechanism of doxorubicin-induced cardiotoxicity is still controversial, free radical formation and mitochondrial disruption seem to represent the main causes (39). Based on recent literature showing that ER $\beta$ activation improves cardiac function $(15,16)$, we analyzed whether silibinin, besides its anti-tumor effect, could also protect cardiomyocytes from doxorubicin-induced toxicity. The AC16 cell line, derived from adult human ventricular cardiomyocytes, was pretreated for $48 \mathrm{~h}$ with $100 \mu \mathrm{M}$ silibinin and then treated with $1 \mu \mathrm{M}$ doxorubicin for $72 \mathrm{~h}$. We observed that silibinin was able to significantly increase cell survival rate after doxorubicin treatment (white columns of bar graph, Figure 4A), reducing at the same time cardiomyocyte apoptosis (grey columns of bar graph, Figure 4A), mitochondrial ROS production (Figure 4B) and 
B

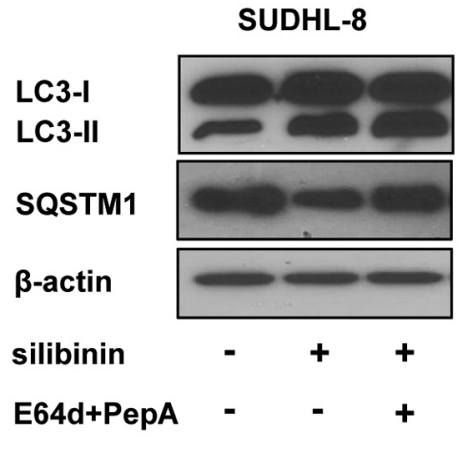

SUDHL-8

\section{$\square$ untreated}

$\square$ silibinin

- silibinin+E64d+PepA
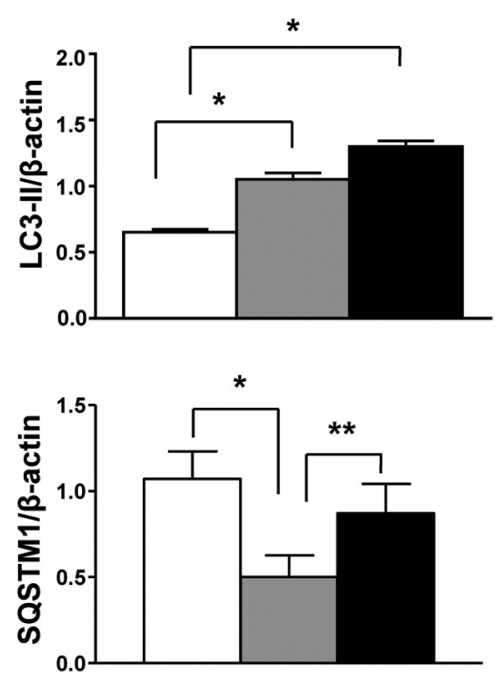

RIVA

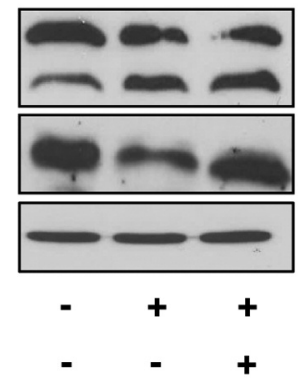

RIVA
SUDHL-6

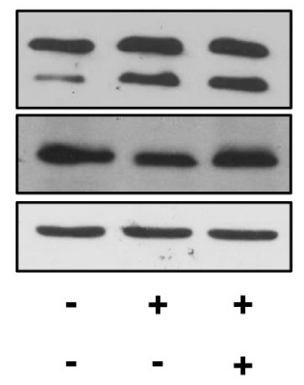

SUDHL-6
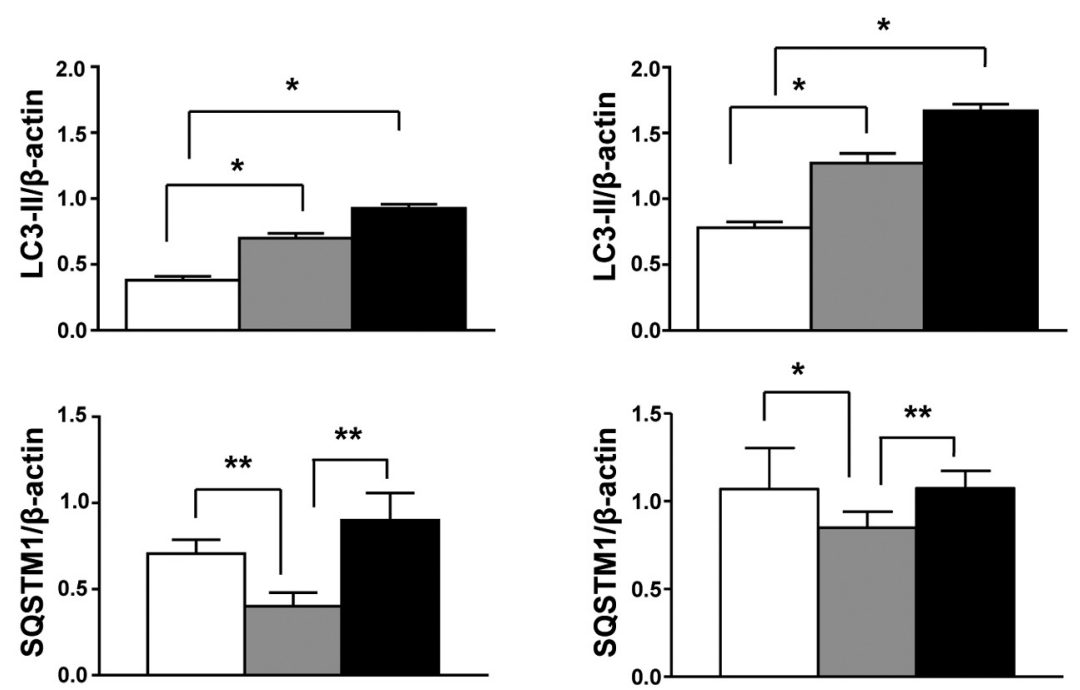

Figure 1. Silibinin induces apoptosis and autophagy in diffuse large B-cell lymphoma (DLBCL) cells. (A) Apoptosis was analyzed using AV and PI detection Kit by flow cytometry in DLBCL cell-lines treated or not with $100 \mu \mathrm{M}$ silibinin for $24 \mathrm{~h}$. Results from one representative experiment out of 5 are shown (left). Numbers reported represent the percentages of AV positive/PI negative (early apoptotic, bottom right quadrant) and PI positive (late apoptotic or necrotic cells, top right and left quadrants). Results are also expressed as the means \pm standard deviation (SD) of 5 independent experiments: $* p<0.05$ vs. untreated cells (right). (B) Western blot analysis of the autophagic markers LC3-II and SQSTM1 in cell lysates from DLBCL cell lines treated or not with $100 \mu \mathrm{M}$ silibinin for $24 \mathrm{~h}$, with or without the lysosomal inhibitors E64d and PepA. For each cell line, blots shown are representative of 5 independent experiments (top). Densitometry analysis of LC3-II and SQSTM1 protein levels relative to $\beta$-actin is also shown (bottom). Values are expressed as mean $\pm S D ; * p<0.05$ and $*^{*} p<0.01$ vs. untreated cells. AV, Annexin V; PI, propidium iodide; LC3-II, microtubule-associated protein 1 light chain 3; SQSTM1, sequestosome 1; FITC, fluorescein isothiocyanate; PE, phycoerythrin.

mitochondria membrane depolarization (Figure 4C) associated with doxorubicin treatment.

In the myocardium, stress-fiber alteration plays a role in cardiomyocyte contractile dysfunction and cardiomyopathy (40). For this reason, we also analyzed the effects of doxorubicin in AC16 cardiomyocytes by performing a qualitative analysis of the microfilament system organization, responsible for cell contraction, by fluorescence microscopy.
As shown in Figure 4D, treatment with doxorubicin was responsible for a strong alteration in actin/myosin organization. In particular, cardiomyocytes lost their bipolar shape along with the compromised orientation of the stress fibers. In addition, the co-localization actin/myosin observed both in untreated cells and silibinin-treated cells, indicated by the yellow fluorescence, was almost completely lost in doxorubicin-treated cells (third picture, compare with first 
A

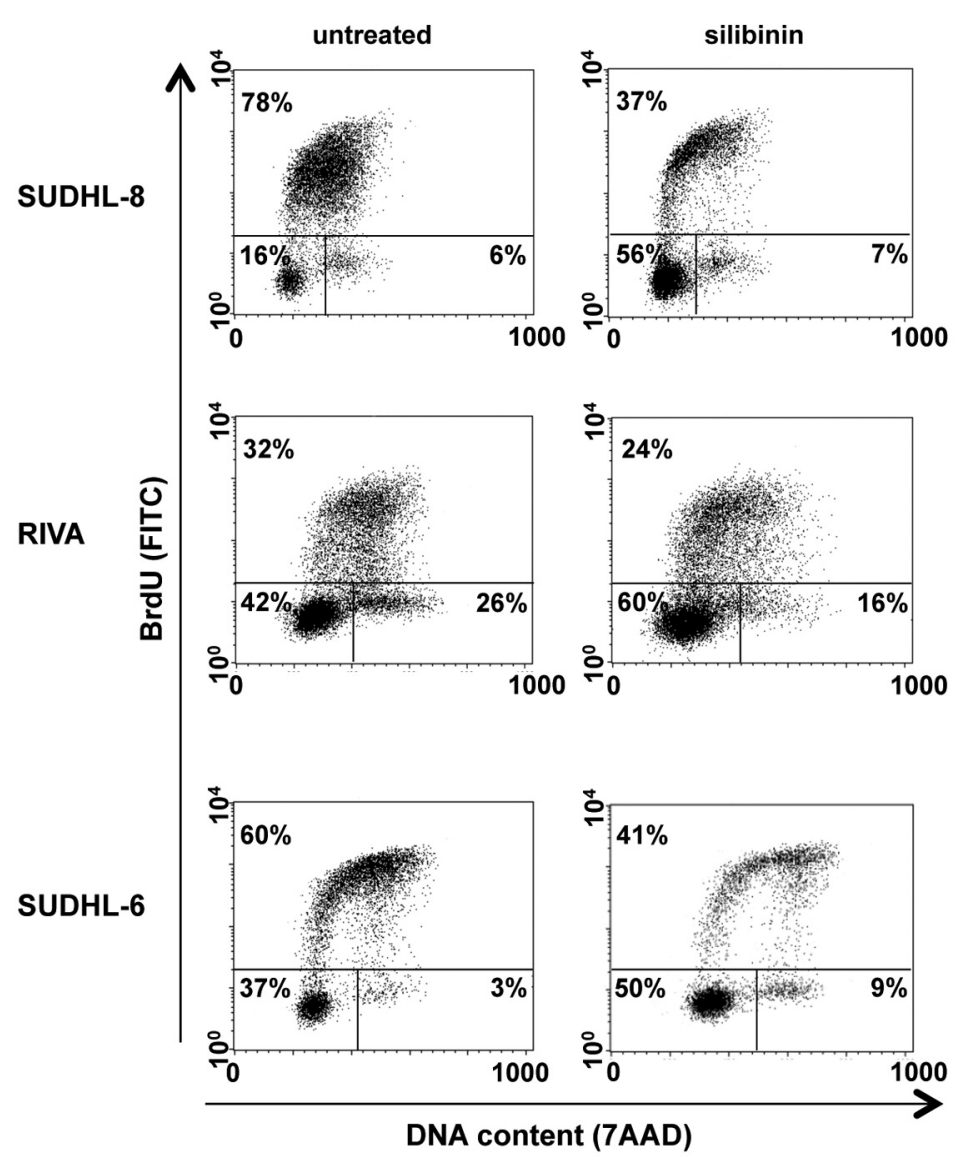

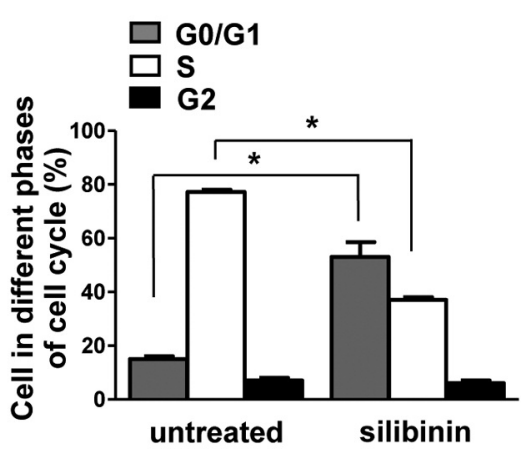
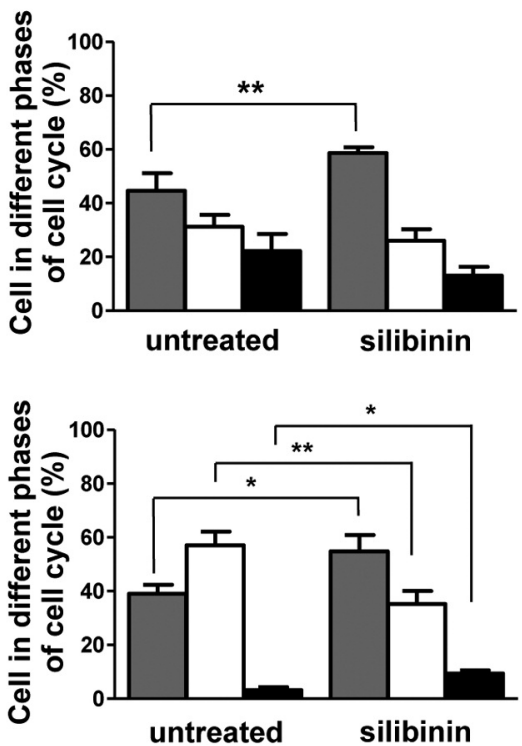

Figure 2. Continued and second picture showing control and silibinin treated cells, respectively). Importantly, silibinin was able to counteract the cytoskeleton alterations induced by doxorubicin (Figure 4D, fourth picture).

\section{Discussion}

In this study, we found that silibinin was able to impact DLBCL cell fate causing in vitro cell apoptosis and autophagy, inducing $\mathrm{G}_{0} / \mathrm{G}_{1}$ cell-cycle arrest, and reducing cell proliferation. It also induced in in vivo experiments in DLBCL cells engrafted in immunodeficient mice cell death and autophagy, and significantly reduced tumor size. In addition, silibinin was able to reduce doxorubicin-induced cardiomyocyte cell death, reducing at the same time, mitochondrial ROS production, mitochondria membrane depolarization and cytoskeleton alterations associated with doxorubicin treatment. The originality of this study consists in the exploration of the possible use of the natural ER $\beta$ agonist silibinin as a therapeutic adjuvant for patients with DLBCL to slow-down the growth of lymphoma and at the same time, to protect human cardiomyocytes from the damage caused by doxorubicin.

In recent years, estrogen and its receptors have attracted extensive attention as potential targets for treating different cancers including hematological malignancies (12, 41, 42). In particular, several studies suggested a key role for ER $\beta$ in cancer suppression promoting apoptosis and autophagy, and inhibiting cell proliferation $(6,43-47)$. In this context, different phytoestrogens, that display a selective ER $\beta$ agonistic activity, including silibinin, have been investigated for their ability to enhance the efficacy of chemotherapy and alleviate the side effects of cancer chemotherapy (23-26). The suppressive effects of phytoestrogens on tumor growth are due to their impact on multiple molecular pathways associated with the development and progression of cancer, including autophagic and apoptotic pathways $(26,48)$.

Autophagy is a selective catabolic process that displays a key role both in basal turnover of altered cellular components 

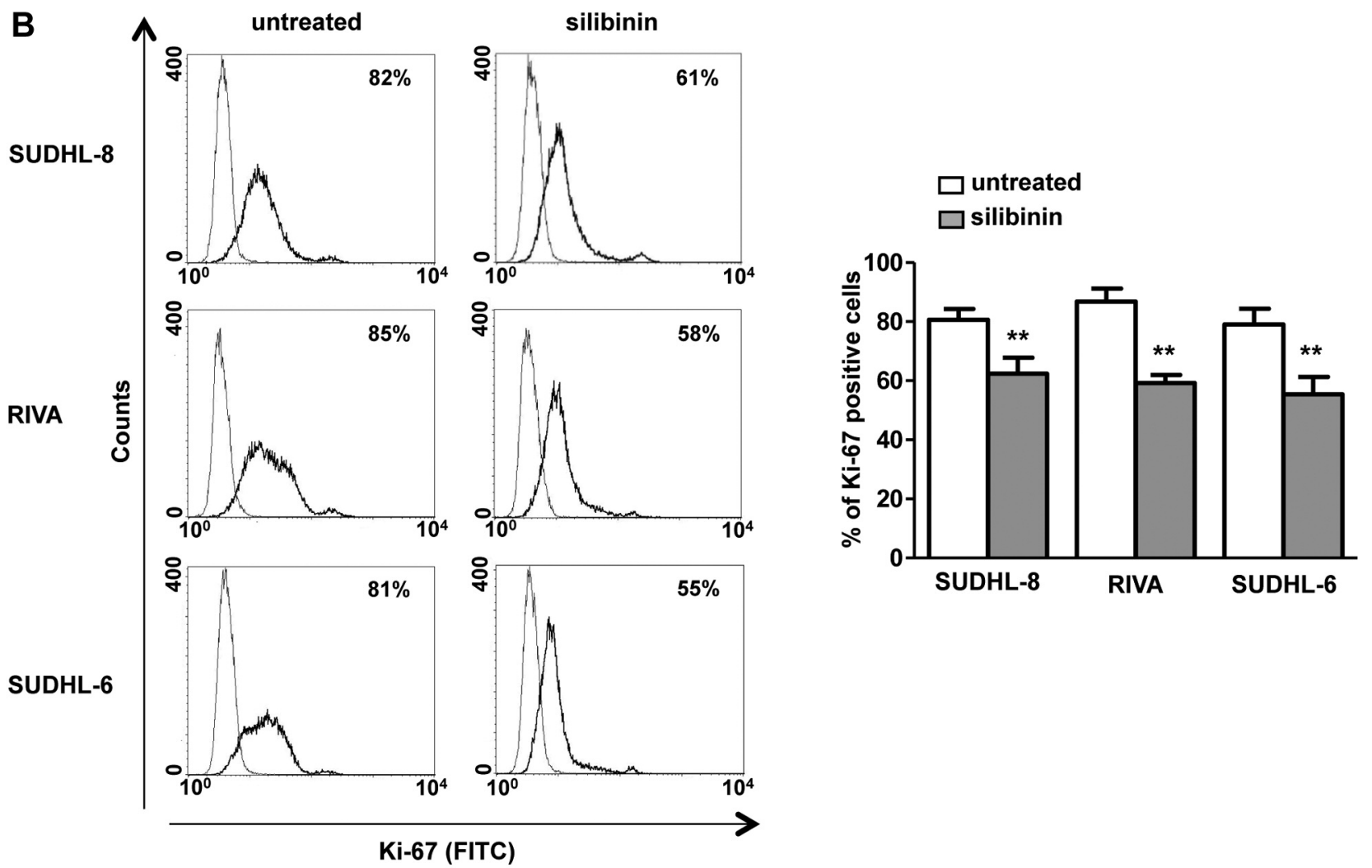

Figure 2. Silibinin alters cell-cycle progression and proliferation of diffuse large B-cell lymphoma (DLBCL) cells. (A) Cell-cycle progression was evaluated by flow cytometry using the BrdU/anti-BrdU method in synchronized DLBCL cell lines treated or not with $100 \mu M$ silibinin for 24 h. Results from one representative experiment out of 5 are shown (left). Data are also reported as mean $\pm S D$ (right), *p<0.05 and **p<0.01 vs. untreated cells. (B) Cell proliferation was evaluated by flow cytometry measuring Ki-67 nuclear antigen expression in DLBCL cells treated or not with $100 \mu \mathrm{M}$ silibinin for $24 \mathrm{~h}$. Results from one representative experiment out of 5 are shown (left). Data are also reported as mean $\pm S D$ (right), ${ }^{* *} p<0.01$ vs. untreated cells. BrdU, 5-bromo-2-deoxy-uridine; 7-AAD, 7-aminoactinomycin D; FITC, fluorescein isothiocyanate; PE, phycoerythrin.

and in counteracting stressful dysmetabolic conditions (37). Notably, autophagy can exert anti- or pro-tumor activities depending on the specific context (49-51). In particular, defective autophagy has been involved in some lymphoid malignancies and, hence, the use of drugs able to induce autophagy is expected to be an effective anticancer strategy (52). In lymphoma, autophagy induction could negatively impact tumor growth through a specific elimination of growthpromoting factors, complexes and organelles, thus impairing cell proliferation (53). Accordingly, in a recent study, we observed in Hodgkin's lymphoma a direct link between autophagy induction and inhibition of tumor growth, triggering ER $\beta$ by the synthetic compound diarylpropionitrile (7). Herein, in line with these previous data, we observed that $\operatorname{ER} \beta$ activation by the natural ER $\beta$ agonist silibinin was associated with an increase of autophagy and a block of cellcycle progression with a reduction of DLBCL proliferation. Besides displaying a cytostatic, pro-autophagic effect, silibinin induced apoptotic cell death, thus also showing a cytotoxic action on tumor. Since insufficient apoptosis is considered to be one of the main factors of drug resistance, the pro-apoptotic effect of this compound allows us to suggest its usage also to overcome chemotherapy resistance often observed in DLBCL patients treated with R-CHOP (2).

In addition to its anti-tumor effect, we observed that silibinin plays a cardioprotective activity in human cardiomyocytes treated with doxorubicin. Cardiac adverse effects of anthracyclines were documented soon after their discovery, however simple aspects related to management of their cardiotoxicity remain uncertain (4). Of note, the prevalence of anthracycline-induced cardiotoxicity is highly variable, but cumulative anthracycline dose is consistently documented as relevant risk factor. With the significant increase in survival of cancer patients, the field of cardio-oncology is continually expanding to enable the prevention and treatment of chemotherapy-induced 
A

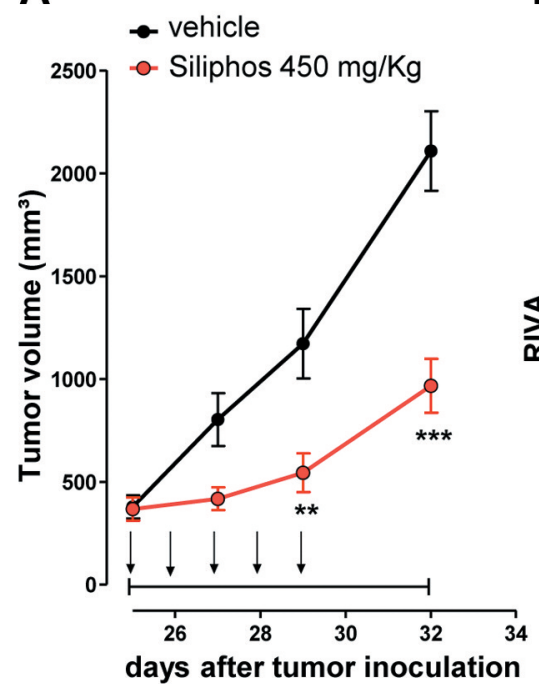

B

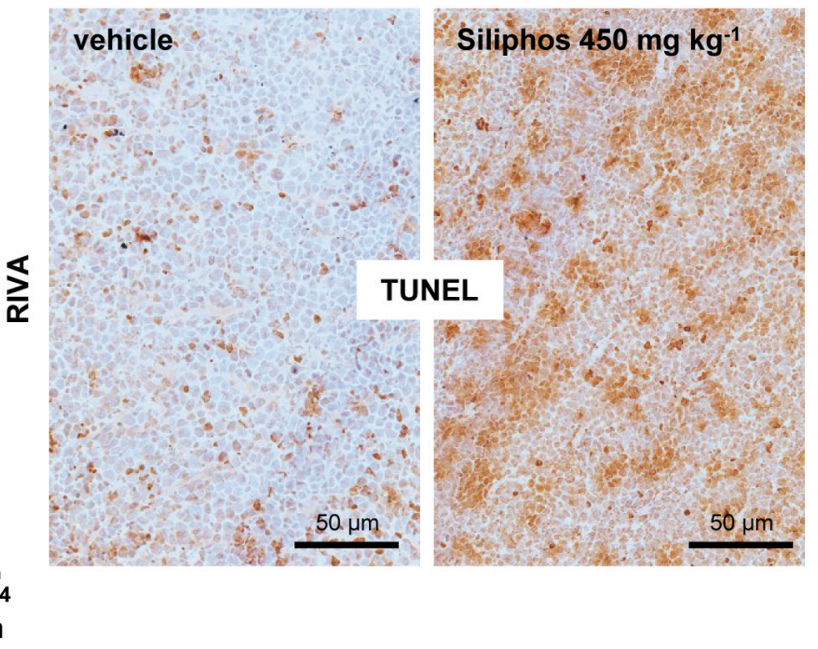

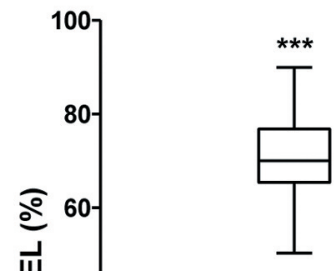

岁

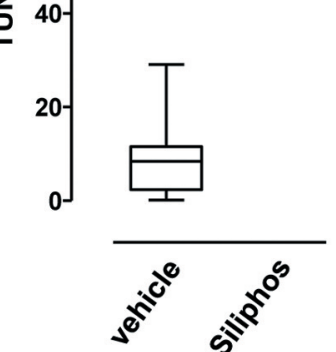

C

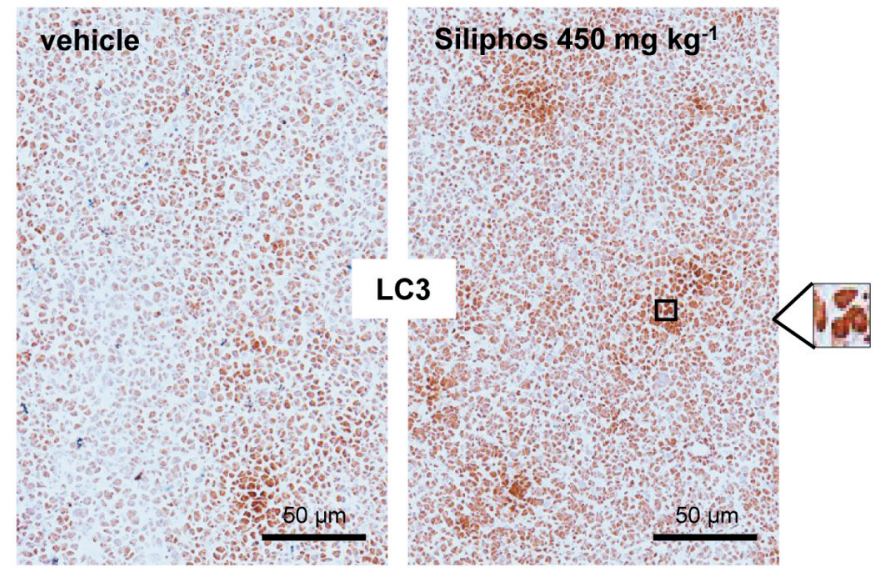

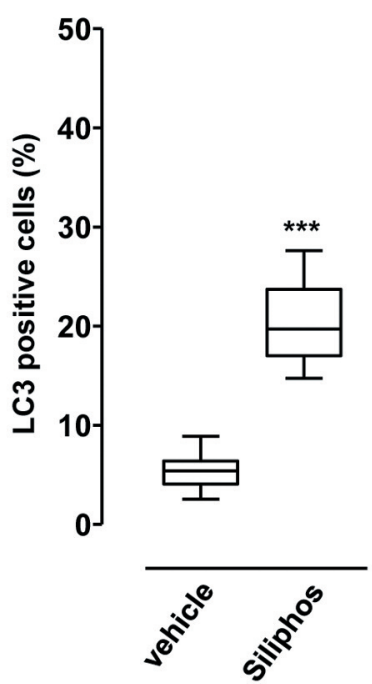

Figure 3. Silibinin induces growth inhibition and autophagy in diffuse large B-cell lymphoma (DLBCL) xenografts in NOD/SCID/IL2Rg-/- mice. (A) NSG mice bearing 100-mm3 RIVA tumor nodules were randomly assigned to receive 5-day treatment with Siliphos by oral gavage (450 mg $\mathrm{kg}^{-1}$, red) or vehicle control (black). Black arrows indicate Siliphos treatment administration. The mean \pm standard error of the mean (SEM) tumor volumes are shown. $* * p<0.01$ and $* * * p<0.001$ vs. vehicle controls. $(B-C)$ Representative histological images and quantification of TUNEL $(B)$ and LC3 (C) staining of RIVA tumors treated with Siliphos (450 $\mathrm{mg} \mathrm{kg}^{-1} /$ day, 5 days) or vehicle control. Cell death was detected by TUNEL staining and autophagy by LC3 positive signals as brown staining within the tumor. Objective lens, 0.75 numerical aperture dry objective; original magnification, 20x. Scale bar, $50 \mu \mathrm{m}$. The TUNEL and LC3 positive cells in the sections were analyzed by automated data collection using a computer-assisted system (Cell^F; Olympus). The percentage of the area that was immunoreactive-positive was calculated for 30 randomly selected fields of each slide at high magnification $(400 x)$. ***p<0.001. NSG, NOD/SCID/IL2Rg-/-; LC3, microtubule-associated protein 1 light chain 3.

cardiotoxicity. In addition to genetic and individual factors of frailty, recent cardio-oncology studies show that, especially in children, female sex is more vulnerable to the cardiotoxic effects of anthracyclines (55). On the contrary, in reproductive age, the female sex would seem, at least in part, to be protected from the heart damage induced by anthracyclines thanks to the quenching of the cardiotoxicity induced by estrogens (56). 
A

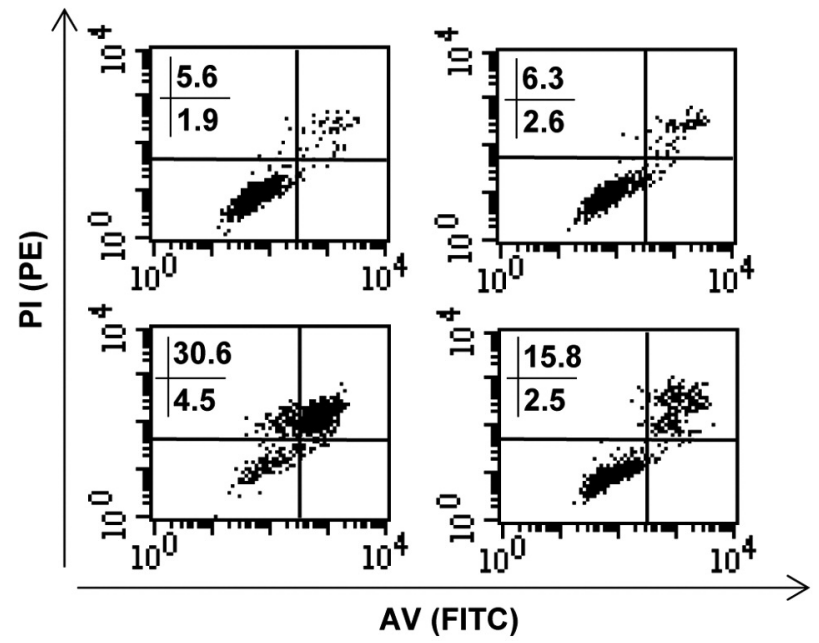

B

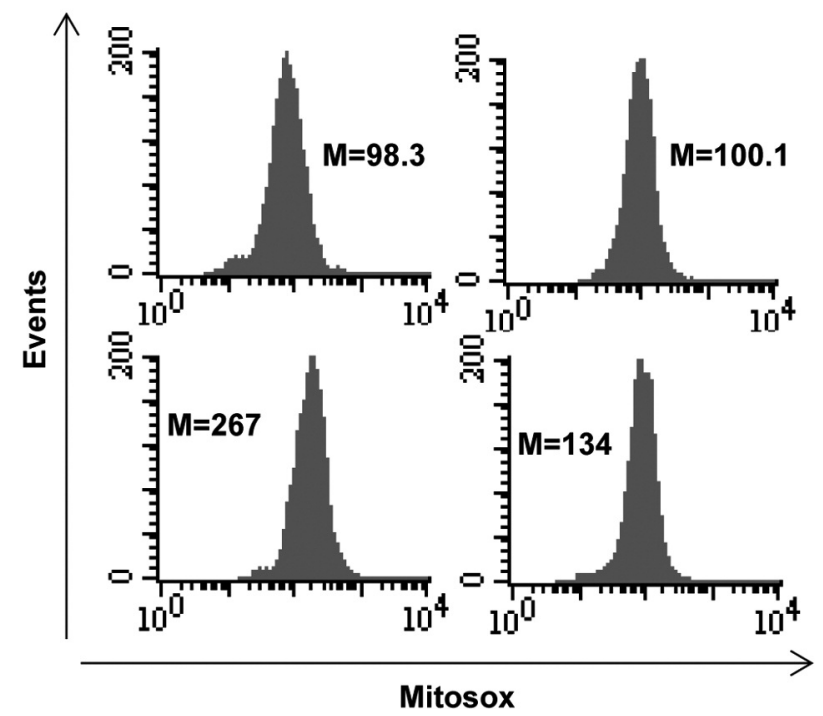

C

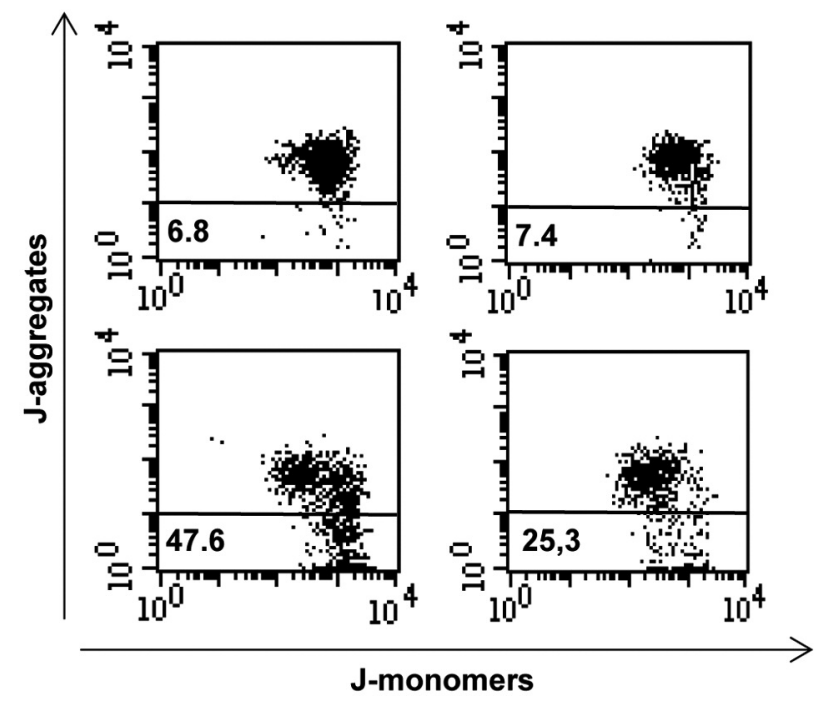

AV positive

Calcein-AM positive

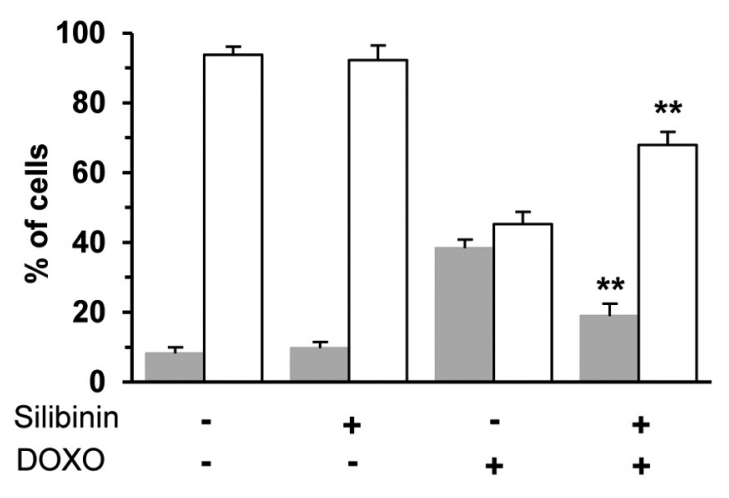

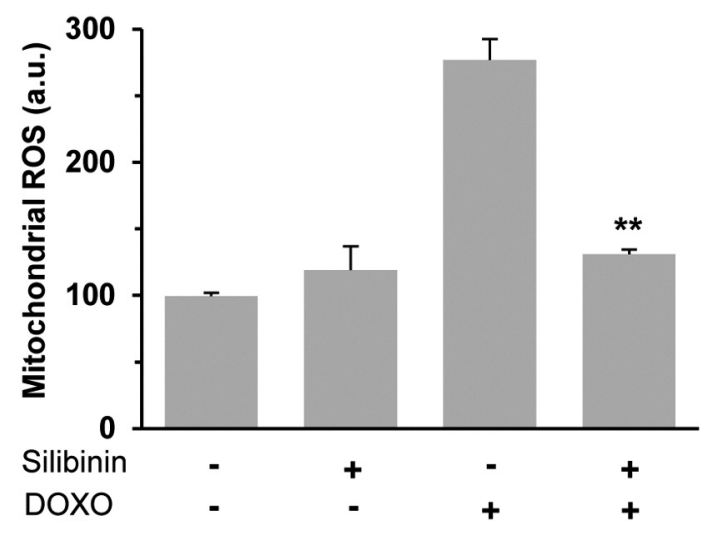

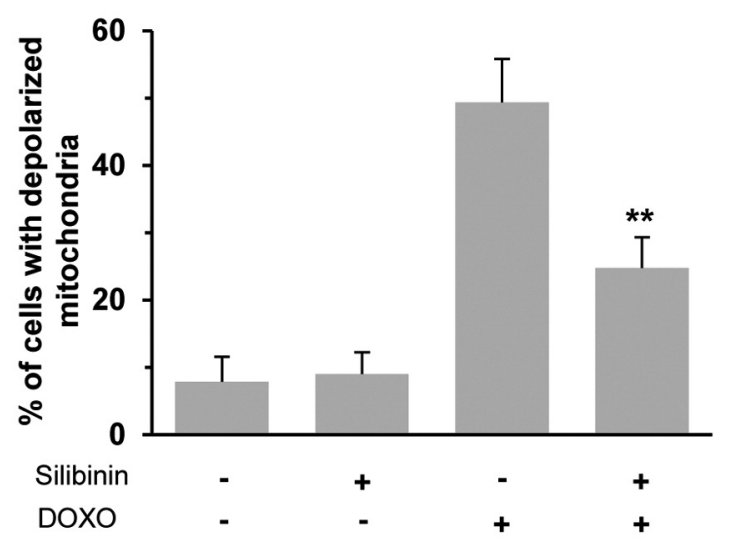

Figure 4. Continued 
D
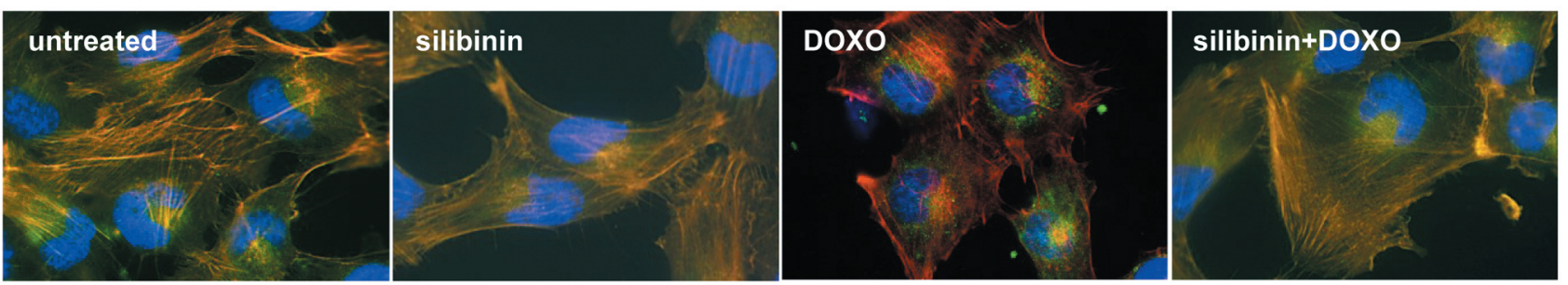

Figure 4. Silibinin protects cardiomyocytes from doxorubicin-mediated toxicity. (A) Flow cytometry analysis after cell staining with AV and PI. Results from 1 representative experiment out of 3 are shown (left). The reported numbers represent the percentages of AV positive/PI negative (early apoptotic, bottom right quadrant) and AV/PI double positive (late apoptotic or necrotic cells, top right and left quadrants) cells. Bar graph shows the mean \pm SD of the results obtained from 3 independent experiments performed after cell staining with AV and PI (grey columns) or Calcein-AM (white columns). $* * p<0.01 \mathrm{vs}$. doxorubicin-treated cells. (B) Representative histograms of the cytofluorimetric analysis of mitochondrial ROS production, performed by using the MitoSox probe. Bar graph shows the mean $\pm S D$ of the results obtained from 3 independent experiments expressed as median fluorescence intensity (arbitrary units, a.u.). ${ }^{*} p<0.01 \mathrm{vs}$. doxorubicin-treated cells. (C) Representative dot plots of the cytofluorimetric analysis of mitochondrial membrane potential, performed by using JC-1. Numbers under lines indicate the percentage of cells with depolarized mitochondrial membrane. Bar graph shows the mean $\pm S D$ of the results obtained from 3 independent experiments. $* * p<0.01 v s$. doxorubicin-treated cells. (D) Representative micrographs obtained by intensified video microscopy after tetramethyl-rhodamine-phalloidin (red)/myosin (green)/Hoechst (blue) triple staining of AC16 cardiomyocytes untreated (control, first picture) or treated with silibinin (second picture), doxorubicin (third picture) or silibinin/doxorubicin association (fourth picture). Yellow fluorescence indicates actin/myosin co-localization. AV, Annexin V; PI, propidium iodide; DOXO, doxorubicin; JC-1, 5-5',6-6'-tetrachloro-1,1',3,3'-tetraethyl benzimidazole-carbocyanine iodide probe; FITC, fluorescein isothiocyanate; PE, phycoerythrin.

Currently, the total cumulative dose of doxorubicin represents the only empirical criterion on the basis of which cardiotoxic effects can be predicted (57) and which actually determines the maximum dose that can be used in the therapy of cancer (58). On the other hand, the reduction beyond certain limits of the dose of doxorubicin, compatible with a reduction of the cardiotoxic effects, would substantially limit its curative effects. Therefore, those drugs or natural compounds capable of limiting the toxic effects of doxorubicin without decreasing its therapeutic efficacy, or hopefully, increasing it so as to be able to reduce the concentration useful for anticancer purposes, are particularly promising.

Some previous studies have demonstrated a cardioprotective effect of silibinin against doxorubicin-induced heart damage in rats $(17,27-29)$. This is the first time, to our knowledge, that the cardioprotective effect of this compound was confirmed in human cardiomyocytes. Of note, silibinin has also been previously demonstrated to increase the chemosensitivity of NHL cells to doxorubicin, suggesting that the combination of silibinin plus doxorubicin would work better than doxorubicin alone in NHL therapy $(24,54)$. In this context, additional studies are necessary to assess the possibility of reducing standard dosage of doxorubicin using silibinin as therapeutic adjuvant.

\section{Conclusion}

On the basis of the data reported in this study, silibinin was shown: (i) to exert an antitumor action per se both in vitro and in vivo, and (ii) to have a significant protective effect on the toxicity induced by doxorubicin on cardiomyocytes in vitro. These data can lay the foundation for the design of clinical trials aimed at assessing the ability of silibinin: (i) to reduce the standard dosage of chemotherapy drugs, when used in association, thanks to its antitumor potential, and (ii) to avoid the reduction or suspension of chemotherapy due to cardiotoxicity, considering its cardioprotective effects. In conclusion, silibinin can be considered a potentially useful adjuvant compound for the treatment of DLBCL. In future clinical studies, it will be mandatory to analyze data disaggregated by sex and age. In fact, these determinants, as mentioned above, can play an important role in the response to drugs in general, and to silibinin in particular, precisely in consideration of its agonist effect on ER $\beta$.

\section{Conflicts of Interest}

The research was conducted in the absence of any commercial or financial relationships that could be construed as a potential conflict of interest.

\section{Authors' Contributions}

MP and EO contributed significantly to the design of the work, data interpretation and manuscript preparation. PM supervised in vitro studies and co-wrote the manuscript. MTP, BA, MM and MLD performed in vitro experiments. SLL and GC performed in vivo experiments and co-wrote the manuscript. WM and CCS provided intellectual contribution throughout the study. All Authors read and approved the final manuscript. 


\section{Acknowledgements}

This study may be considered as a tribute to our young researcher Angela Maselli who passed away prematurely during the preparation of this manuscript. Her enthusiastic and skilled contribution was crucial for the realization of this study.

\section{Funding}

This work was supported in part by the Italian Association for Cancer Research (18526 to PM) and Nando \& Elsa Peretti Foundation (NaEPF 2019-042 to PM).

\section{References}

1 Grimm KE and O'Malley DP: Aggressive B cell lymphomas in the 2017 revised WHO classification of tumors of hematopoietic and lymphoid tissues. Ann Diagn Pathol 38: 6-10, 2019. PMID: 30380402. DOI: 10.1016/j.anndiagpath.2018.09.014

2 Klener P and Klanova M: Drug resistance in non-Hodgkin lymphomas. Int J Mol Sci 21(6): 2081, 2020. PMID: 32197371. DOI: $10.3390 / \mathrm{ijms} 21062081$

3 Mondello P and Mian M: Frontline treatment of diffuse large Bcell lymphoma: Beyond R-CHOP. Hematol Oncol 37(4): 333 344, 2019. PMID: 30938848. DOI: 10.1002/hon.2613

4 Johnson SA: Anthracycline-induced cardiotoxicity in adult hematologic malignancies. Semin Oncol 33(3 Suppl 8): S22-S27, 2006. PMID: 16781286. DOI: 10.1053/j.seminoncol.2006. 04.021

5 Yakimchuk K, Iravani M, Hasni MS, Rhönnstad P, Nilsson S, Jondal $\mathrm{M}$ and Okret $\mathrm{S}$ : Effect of ligand-activated estrogen receptor $\beta$ on lymphoma growth in vitro and in vivo. Leukemia 25(7): 11031110, 2011. PMID: 21502954. DOI: 10.1038/leu.2011.68

6 Yakimchuk K, Hasni MS, Guan J, Chao MP, Sander B and Okret S: Inhibition of lymphoma vascularization and dissemination by estrogen receptor $\beta$ agonists. Blood 123(13): 2054-2061, 2014 PMID: 24470591. DOI: 10.1182/blood-2013-07-517292

7 Pierdominici M, Maselli A, Locatelli SL, Ciarlo L, Careddu G, Patrizio M, Ascione B, Tinari A, Carlo-Stella C, Malorni W, Matarrese $\mathrm{P}$ and Ortona $\mathrm{E}$ : Estrogen receptor $\beta$ ligation inhibits Hodgkin lymphoma growth by inducing autophagy. Oncotarget 8(5): 8522-8535, 2017. PMID: 28052027. DOI: 10.18632/ oncotarget.14338

8 Ascenzi P, Bocedi A and Marino M: Structure-function relationship of estrogen receptor alpha and beta: impact on human health. Mol Aspects Med 27(4): 299-402, 2006. PMID: 16914190. DOI: 10.1016/j.mam.2006.07.001

9 Dey P, Barros RP, Warner M, Ström A and Gustafsson JÅ: Insight into the mechanisms of action of estrogen receptor $\beta$ in the breast, prostate, colon, and CNS. J Mol Endocrinol 51(3): T61-T74, 2013. PMID: 24031087. DOI: 10.1530/JME-13-0150

10 Thomas $\mathrm{C}$ and Gustafsson JA: The different roles of ER subtypes in cancer biology and therapy. Nat Rev Cancer 11(8): 597-608, 2011. PMID: 21779010. DOI: 10.1038/nrc3093

11 Shim GJ, Gherman D, Kim HJ, Omoto Y, Iwase H, Bouton D, Kis LL, Andersson CT, Warner $M$ and Gustafsson JA: Differential expression of oestrogen receptors in human secondary lymphoid tissues. J Pathol 208(3): 408-414, 2006. PMID: 16294372. DOI: 10.1002/path.1883
12 Yakimchuk K, Jondal M and Okret S: Estrogen receptor $\alpha$ and $\beta$ in the normal immune system and in lymphoid malignancies. Mol Cell Endocrinol 375(1-2): 121-129, 2013. PMID: 23707618. DOI: 10.1016/j.mce.2013.05.016

13 Yakimchuk K, Norin S, Kimby E, Hägglund H, Warner M and Gustafsson JA: Up-regulated estrogen receptor $\beta 2$ in chronic lymphocytic leukemia. Leuk Lymphoma 53(1): 139-144, 2012. PMID: 21767241. DOI: 10.3109/10428194.2011.605187

14 Faknuam S, Assanasen T, Ruangvejvorachai P, Hanvivadhanakul $\mathrm{P}$, Intragumtornchai $\mathrm{T}$ and Rojnuckarin $\mathrm{P}$ : Estrogen receptor beta expression and prognosis of diffuse large B cell lymphoma. Hematology 23(4): 235-241, 2018. PMID: 29032728. DOI: $10.1080 / 10245332.2017 .1389508$

15 Iorga A, Umar S, Ruffenach G, Aryan L, Li J, Sharma S, Motayagheni N, Nadadur RD, Bopassa JC and Eghbali M: Estrogen rescues heart failure through estrogen receptor Beta activation. Biol Sex Differ 9(1): 48, 2018. PMID: 30376877. DOI: 10.1186/s13293-018-0206-6

16 Schuster I, Mahmoodzadeh S, Dworatzek E, Jaisser F, Messaoudi S, Morano I and Regitz-Zagrosek V: Cardiomyocytespecific overexpression of oestrogen receptor $\beta$ improves survival and cardiac function after myocardial infarction in female and male mice. Clin Sci (Lond) 130(5): 365-376, 2016. PMID: 26608078. DOI: 10.1042/CS20150609

17 Chlopcíková S, Psotová J, Miketová $\mathrm{P}$ and Simánek V: Chemoprotective effect of plant phenolics against anthracyclineinduced toxicity on rat cardiomyocytes. Part I. Silymarin and its flavonolignans. Phytother Res 18(2): 107-110, 2004. PMID: 15022159. DOI: $10.1002 /$ ptr.1415

18 Pokrzywinski KL, Biel TG, Rosen ET, Bonanno JL, Aryal B, Mascia F, Moshkelani D, Mog S and Rao VA: Doxorubicininduced cardiotoxicity is suppressed by estrous-staged treatment and exogenous $17 \beta$-estradiol in female tumor-bearing spontaneously hypertensive rats. Biol Sex Differ 9(1): 25, 2018. PMID: 29907135. DOI: 10.1186/s13293-018-0183-9

19 El-Shitany NA, Hegazy S and El-Desoky K: Evidences for antiosteoporotic and selective estrogen receptor modulator activity of silymarin compared with ethinylestradiol in ovariectomized rats. Phytomedicine 17(2): 116-125, 2010. PMID: 19577454. DOI: 10.1016/j.phymed.2009.05.012

20 Comelli MC, Mengs U, Schneider C and Prosdocimi M: Toward the definition of the mechanism of action of silymarin: activities related to cellular protection from toxic damage induced by chemotherapy. Integr Cancer Ther 6(2): 120-129, 2007. PMID: 17548791. DOI: $10.1177 / 1534735407302349$

21 Dupuis ML, Conti F, Maselli A, Pagano MT, Ruggieri A, Anticoli S, Fragale A, Gabriele L, Gagliardi MC, Sanchez M, Ceccarelli F, Alessandri C, Valesini G, Ortona E and Pierdominici M: The natural agonist of estrogen receptor $\beta$ silibinin plays an immunosuppressive role representing a potential therapeutic tool in rheumatoid arthritis. Front Immunol 9: 1903, 2018. PMID: 30174672. DOI: 10.3389/fimmu.2018.01903

22 Post-White J, Ladas EJ and Kelly KM: Advances in the use of milk thistle (Silybum marianum). Integr Cancer Ther 6(2): 104109, 2007. PMID: 17548789. DOI: $10.1177 / 153473$ 5407301632

23 Zhu XX, Ding YH, Wu Y, Qian LY, Zou H and He Q: Silibinin: a potential old drug for cancer therapy. Expert Rev Clin Pharmacol 9(10): 1323-1330, 2016. PMID: 27362364. DOI: $10.1080 / 17512433.2016 .1208563$ 
24 Zou H, Zhu XX, Zhang GB, Ma Y, Wu Y and Huang DS: Silibinin: an old drug for hematological disorders. Oncotarget 8(51): 89307-89314, 2017. PMID: 29179521. DOI: 10.18632 /oncotarget.19153

25 Agarwal R, Agarwal C, Ichikawa H, Singh RP and Aggarwal BB: Anticancer potential of silymarin: from bench to bed side. Anticancer Res 26(6B): 4457-4498, 2006. PMID: 17201169.

26 Pang X, Zhang X, Jiang Y, Su Q, Li Q and Li Z: Autophagy: Mechanisms and therapeutic potential of flavonoids in cancer. Biomolecules 11(2): 135, 2021. PMID: 33494431. DOI: 10.3390/biom 11020135

27 Rašković A, Stilinović N, Kolarović J, Vasović V, Vukmirović S and Mikov M: The protective effects of silymarin against doxorubicin-induced cardiotoxicity and hepatotoxicity in rats. Molecules 16(10): 8601-8613, 2011. PMID: 21993249. DOI: 10.3390/molecules 16108601

28 Cecen E, Dost T, Culhaci N, Karul A, Ergur B and Birincioglu $\mathrm{M}$ : Protective effects of silymarin against doxorubicin-induced toxicity. Asian Pac J Cancer Prev 12(10): 2697-2704, 2011. PMID: 22320977.

29 Psotová J, Chlopcíková S, Grambal F, Simánek V and Ulrichová J: Influence of silymarin and its flavonolignans on doxorubicin-iron induced lipid peroxidation in rat heart microsomes and mitochondria in comparison with quercetin. Phytother Res 16(Suppl 1): S63-S67, 2002. PMID: 11933142. DOI: 10.1002/ptr.811

30 Razavi BM and Karimi G: Protective effect of silymarin against chemical-induced cardiotoxicity. Iran J Basic Med Sci 19(9): 916-923, 2016. PMID: 27803777.

31 Tamayo C and Diamond S: Review of clinical trials evaluating safety and efficacy of milk thistle (Silybum marianum [L.] Gaertn.). Integr Cancer Ther 6(2): 146-157, 2007. PMID: 17548793. DOI: $10.1177 / 1534735407301942$

32 Kuznetsov AV, Javadov S, Margreiter R, Grimm M, Hagenbuchner J and Ausserlechner MJ: The role of mitochondria in the mechanisms of cardiac ischemia-reperfusion injury. Antioxidants (Basel) 8(10): 454, 2019. PMID: 31590423. DOI: 10.3390/antiox8100454

33 Jordan TL, Maar K, Redhage KR, Misra P, Blancas-Mejia LM, Dick CJ, Wall JS, Williams A, Dietz AB, van Wijnen AJ, Lin Y and Ramirez-Alvarado M: Light chain amyloidosis induced inflammatory changes in cardiomyocytes and adipose-derived mesenchymal stromal cells. Leukemia 34(5): 1383-1393, 2020. PMID: 31796914. DOI: 10.1038/s41375-019-0640-4

34 Matarrese P, Tinari A, Mormone E, Bianco GA, Toscano MA, Ascione B, Rabinovich GA and Malorni W: Galectin-1 sensitizes resting human $\mathrm{T}$ lymphocytes to Fas (CD95)-mediated cell death via mitochondrial hyperpolarization, budding, and fission. J Biol Chem 280(8): 6969-6985, 2005. PMID: 15556941. DOI: $10.1074 /$ jbc.M409752200

35 Matarrese P, Abbruzzese C, Mileo AM, Vona R, Ascione B, Visca P, Rollo F, Benevolo M, Malorni W and Paggi MG: Interaction between the human papillomavirus 16 E7 oncoprotein and gelsolin ignites cancer cell motility and invasiveness. Oncotarget 7(32): 50972-50985, 2016. PMID: 27072581. DOI: 10.18632 /oncotarget.8646

36 Kidd P and Head K: A review of the bioavailability and clinical efficacy of milk thistle phytosome: a silybin-phosphatidylcholine complex (Siliphos). Altern Med Rev 10(3): 193-203, 2005. PMID: 16164374.

37 Klionsky DJ, Abdel-Aziz AK, Abdelfatah S, Abdellatif M, et al: Guidelines for the use and interpretation of assays for monitoring autophagy (4th edition)1. Autophagy 17(1): 1-382, 2021. PMID: 33634751. DOI: $10.1080 / 15548627.2020 .1797280$

38 Yoshii SR and Mizushima N: Monitoring and measuring autophagy. Int J Mol Sci 18(9): 1865, 2017. PMID: 28846632. DOI: 10.3390/ijms18091865

39 Octavia Y, Tocchetti CG, Gabrielson KL, Janssens S, Crijns HJ and Moens AL: Doxorubicin-induced cardiomyopathy: from molecular mechanisms to therapeutic strategies. J Mol Cell Cardiol 52(6): 1213-1225, 2012. PMID: 22465037. DOI: 10.1016/j.yjmcc.2012.03.006

40 Bravo-Cordero JJ, Magalhaes MA, Eddy RJ, Hodgson L and Condeelis J: Functions of cofilin in cell locomotion and invasion. Nat Rev Mol Cell Biol 14(7): 405-415, 2013. PMID: 23778968. DOI: $10.1038 / \mathrm{nrm} 3609$

41 Mal R, Magner A, David J, Datta J, Vallabhaneni M, Kassem M, Manouchehri J, Willingham N, Stover D, Vandeusen J, Sardesai S, Williams N, Wesolowski R, Lustberg M, Ganju RK, Ramaswamy B and Cherian MA: Estrogen Receptor Beta (ER $\beta$ ): A Ligand Activated Tumor Suppressor. Front Oncol 10: 587386, 2020. PMID: 33194742. DOI: 10.3389/fonc.2020.587386

42 Warner M, Huang B and Gustafsson JA: Estrogen receptor $\beta$ as a pharmaceutical target. Trends Pharmacol Sci 38(1): 92-99, 2017. PMID: 27979317. DOI: 10.1016/j.tips.2016.10.006

43 Guido C, Panza S, Santoro M, Avena P, Panno ML, Perrotta I, Giordano F, Casaburi I, Catalano S, De Amicis F, Sotgia F, Lisanti MP, Andò S and Aquila S: Estrogen receptor beta $(\mathrm{ER} \beta)$ produces autophagy and necroptosis in human seminoma cell line through the binding of the Sp1 on the phosphatase and tensin homolog deleted from chromosome 10 (PTEN) promoter gene. Cell Cycle 11(15): 2911-2921, 2012. PMID: 22810004. DOI: $10.4161 / \mathrm{cc} .21336$

44 Ruddy SC, Lau R, Cabrita MA, McGregor C, McKay BC, Murphy LC, Wright JS, Durst T and Pratt MA: Preferential estrogen receptor $\beta$ ligands reduce $\mathrm{Bcl}-2$ expression in hormoneresistant breast cancer cells to increase autophagy. Mol Cancer Ther 13(7): 1882-1893, 2014. PMID: 24785256. DOI: 10.1158/1535-7163.MCT-13-1066

45 Paterni I, Granchi C, Katzenellenbogen JA and Minutolo F: Estrogen receptors alpha $(\mathrm{ER} \alpha)$ and beta $(\mathrm{ER} \beta)$ : subtypeselective ligands and clinical potential. Steroids 90: 13-29, 2014. PMID: 24971815. DOI: 10.1016/j.steroids.2014.06.012

46 Roemer K and Pfreundschuh M: How do estrogens control lymphoma? Blood 123(13): 1980-1981, 2014. PMID: 24677401. DOI: 10.1182/blood-2014-02-554691

47 Yang ZM, Yang MF, Yu W and Tao HM: Molecular mechanisms of estrogen receptor $\beta$-induced apoptosis and autophagy in tumors: implication for treating osteosarcoma. J Int Med Res 47(10): 46444655, 2019. PMID: 31526167. DOI: 10.1177/0300060519871373

48 Abotaleb M, Samuel SM, Varghese E, Varghese S, Kubatka P, Liskova A and Büsselberg D: Flavonoids in cancer and apoptosis. Cancers (Basel) 11(1): 28, 2018. PMID: 30597838. DOI: $10.3390 /$ cancers 11010028

49 Singh SS, Vats S, Chia AY, Tan TZ, Deng S, Ong MS, Arfuso F, Yap CT, Goh BC, Sethi G, Huang RY, Shen HM, Manjithaya R and Kumar AP: Dual role of autophagy in hallmarks of cancer. Oncogene 37(9): 1142-1158, 2018. PMID: 29255248. DOI: 10.1038/s41388-017-0046-6

50 White E: Deconvoluting the context-dependent role for autophagy in cancer. Nat Rev Cancer 12(6): 401-410, 2012. PMID: 22534666. DOI: 10.1038/nrc3262 
51 Galluzzi L, Pietrocola F, Bravo-San Pedro JM, Amaravadi RK, Baehrecke EH, Cecconi F, Codogno P, Debnath J, Gewirtz DA, Karantza V, Kimmelman A, Kumar S, Levine B, Maiuri MC, Martin SJ, Penninger J, Piacentini M, Rubinsztein DC, Simon HU, Simonsen A, Thorburn AM, Velasco G, Ryan KM and Kroemer G: Autophagy in malignant transformation and cancer progression. EMBO J 34(7): 856-880, 2015. PMID: 25712477. DOI: $10.15252 / \mathrm{embj} .201490784$

52 Pierdominici M, Barbati C, Vomero M, Locatelli SL, CarloStella C, Ortona E and Malorni W: Autophagy as a pathogenic mechanism and drug target in lymphoproliferative disorders. FASEB J 28(2): 524-535, 2014. PMID: 24196588. DOI: 10.1096/fj.13-235655

53 Neufeld TP: Autophagy and cell growth - the yin and yang of nutrient responses. J Cell Sci 125(Pt 10): 2359-2368, 2012. PMID: 22649254. DOI: $10.1242 /$ jcs. 103333

54 Molavi O, Samadi N, Wu C, Lavasanifar A and Lai R: Silibinin suppresses NPM-ALK, potently induces apoptosis and enhances chemosensitivity in ALK-positive anaplastic large cell lymphoma. Leuk Lymphoma 57(5): 1154-1162, 2016. PMID: 26133723. DOI: 10.3109/10428194.2015.1068306

55 Bansal N, Amdani SM, Hutchins KK and Lipshultz SE: Cardiovascular disease in survivors of childhood cancer. Curr Opin Pediatr 30(5): 628-638, 2018. PMID: 30124579. DOI: 10.1097/MOP.0000000000000675
56 Pokrzywinski KL, Biel TG, Rosen ET, Bonanno JL, Aryal B, Mascia F, Moshkelani D, Mog S and Rao VA: Doxorubicininduced cardiotoxicity is suppressed by estrous-staged treatment and exogenous $17 \beta$-estradiol in female tumor-bearing spontaneously hypertensive rats. Biol Sex Differ 9(1): 25, 2018. PMID: 29907135. DOI: 10.1186/s13293-018-0183-9

57 Colombo A, Cipolla C, Beggiato M and Cardinale D: Cardiac toxicity of anticancer agents. Curr Cardiol Rep 15(5): 362, 2013. PMID: 23512625. DOI: 10.1007/s11886-013-0362-6

58 Cho H, Lee S, Sim SH, Park IH, Lee KS, Kwak MH and Kim HJ: Cumulative incidence of chemotherapy-induced cardiotoxicity during a 2-year follow-up period in breast cancer patients. Breast Cancer Res Treat 182(2): 333-343, 2020. PMID: 32468335. DOI: 10.1007/s10549-020-05703-5

Received November 24, 2021

Revised December 29, 2021

Accepted January 10, 2022 